\title{
Past Experiences, Present Beliefs, Future Practices: Using Narratives to Re(present) Leadership Educator Identity
}

\author{
Kerry L. Priest, Ph.D. \\ Kansas State University \\ Corey Seemiller, Ph.D. \\ Wright State University
}

\begin{abstract}
In an effort to better understand leadership educator preparation, this qualitative study explores leadership educators' identity constructions, or (re)presentations of experiences, beliefs, and practices that contribute to one's professional identity. We used three narrative approaches (storytelling, symbolic interactionism, and anticipatory reflection) to capture short stories of leadership educators' lived experiences and life perspectives. Analysis of these narratives illustrate the kinds of past experiences that led to shifts in thinking or practice. Leadership education was seen as a process of leadership development, with teachers and students both exercising leadership. And participants' reflection on their intentions for future practice emphasize learning that is both personal (relational) and procedural (developing knowledge and skills). Findings offer insight into recommendations for intentional professional development experiences and future research.
\end{abstract}

\section{Introduction}

The field of leadership education has made progress on understanding who teaches leadership and requirements of the profession. Spurred on by a perceived lack of training and resources within the field, there has been increased conversation and scholarship around professional legitimization (e.g., Andenoro et al., 2013; Sowcik, Lindsey \& Rosch, 2013), with an emphasis on identifying pedagogical best-practices for leadership education (e.g., Jenkins, 2012). Jenkins and Owens (2016) point to the Council for the Advancement of Standards in Higher Education's (2009) Standards for Student Leadership Programs and the International Leadership Association's (2009) Guiding Questions document as current, collaboratively generated resources that outline professional competencies and considerations related to knowledge (e.g., knowledge of leadership theories, models, philosophies) and teaching and learning practices (e.g., role of context, assessment practices). While these documents state what faculty and student affairs leadership educators should know and $d o$, there is little known about pathways of preparation and socialization into the profession: the process of becoming $a$ leadership educator (Jenkins \& Owen, 2016).

While specific literature on leadership educator preparation is sparse, much has been written about teacher preparation: the process of becoming and being a teacher. Therefore, we situate our study around three premises from teacher education literature. First, the process of 
becoming a teacher is a process of professional identity development (Danielwicz, 2001; Sachs, 2005). Teacher professional identity has been described as a dynamic process of interpretation and re-interpretation of the experience of learning to be a teacher (Beijaard, Meijer, \& Verloop, 2004). Becoming a teacher requires more than acquiring new knowledge and trying out new teaching practices; it involves developing new understandings of what it means to be a teacher (Sachs, 2005). Professional identity is the negotiation of self-views, others' perceptions or expectations, and the meaning of a teacher's role or position within society (Gee, 2000; Sutherland, Howard, \& Markauskaite, 2010). Viewing leadership educators as teachers, Seemiller \& Priest (2015) suggest that attention to - and intentional development of professional identity is a missing piece in leadership educator preparation.

Second, teacher professional identities are socially constructed, and legitimized through interactions and participation with students, colleagues, and professional communities (Coldron \& Smith, 1999; Sutherland, Howard, \& Markauskaite, 2010). Identity constructions (beliefs about self as teacher) are embedded in multiple contexts and social relationships that shape teachers' own ideas of what teaching is and is for, and what teachers should know or do (Sachs, 2001; 2005; Shultz \& Ravich, 2013; Wenger 1998). Understanding the contexts, experiences, and relational influences in which leadership educators' learn to teach can also provide insight into leadership educators' professional identity constructions.

Third, teacher professional identity is constructed through narrative reflection and meaning-making processes such as storytelling and dialogue (e.g., Ackerman, Maslin-Strowski, \& Christenson; Shultz \& Ravich, 2013). Bruner (2002) emphasizes that the construction of self is narrative; selfhood is a product of our own story-making. In order to adopt a critically reflective stance towards practice, one must analyze assumptions about teaching learning and learning through multiple lenses including our own and others' stories of experience (Brookfield, 2015). Connelly and Clandinin (1990) described how narratives are essential in the study of educators' experiences. "Education and educational research is the construction and reconstruction of personal and social stories; learners, teachers, and researchers are storytellers and characters in their own and others' stories" (1990, p. 2). Drawing from this perspective, narrative approaches offer a unique opportunity to examine and make meaning of one's personal experience as a leadership educator, and also reveal collective themes and discourses that can inform the design of intentional leadership educator professional development experiences.

Purpose. We sought to describe professional identity constructions of leadership educators participating in a professional development experience. Identity constructions are defined in this study as narrative representations of experiences, beliefs, and practices that contribute to one's professional identity. The study was guided the following research questions:

1. How do participants describe critical moments in their leadership educator journey?

2. How do participants describe their beliefs about leadership education?

3. How do participants express intentions for future leadership education practice?

The field of leadership education can benefit from the outcomes of this study. Beauchamp and Thomas (2009) point out that professional identity can be used as an analytic 
lens through which to examine influences on teaching beliefs and practices, as well as a way for teachers to organize their professional lives (explain or make sense of in relation to others and the world). Scholarship of teacher identity can inform better design of teacher education programs (Beauchamp \& Thomas, 2009). Similarly, the process of reflective self-exploration through narrative approaches not only creates the conditions for self-understanding, but also surfaces common concerns and experiences among leadership educator professionals. When supervisors, mentors, conference coordinators, and other educators understand the concerns, fears, issues, and experiences of new and emerging professionals, they can provide appropriate support and resources. Our findings can inform the design of intentional professional preparation programs and developmental experiences. And, an increased level of knowledge and connection to other leadership educators may lead to enhanced teaching practices and increased scholarly contributions to the field.

\section{Literature Review}

Leadership Educator Professional Identity. Teacher professional identity research (both theoretical and empirical) has been focused around three primary categories: (1) describing processes of identity formation, (2) identifying characteristics of identity, and (3) (re)presenting identity through teachers' stories of experience (Beijaard et al., 2004). Drawing from this research situated in teaching and teacher education, Seemiller and Priest (2015) proposed a model of leadership educator professional identity formation. The Leadership Educator Professional Identity Development (LEPID) model suggests that leadership educators hold a complex professional identity shaped by critical experiences and influences; for example, personal and social identities, personal agency, perceptions/beliefs, expertise, communities of practice, and context. As a result of experiences and ongoing influences, individuals may move forwards or backwards through "identity spaces" (or stages) of exploration, experimentation, validation, and confirmation (2015, p. 135).

When Seemiller and Priest (2017) further analyzed leadership educators stories of professional experience, they found a consistent, linear pattern of progression through identity spaces, including evidence of a pre-exploration space. Educators' stories also illustrated characteristics of complexity within each space, including experiential, cognitive, and emotional dimensions, and highlighted personal influences and professional landscapes that shaped educators' views of self. The study's findings reinforced Beijaard et al.'s (2004) claim that stories of experience not only offer insight into processes of development, but also highlight the relationship between educators' beliefs and practices.

Using Narratives to Explore Professional Identity. (Re)telling stories through narrative approaches have been used as methods to study teacher discourses and knowledge (Nespor \& Barylske, 1991), examine the role of narrative in teacher learning and identity development (Schultz \& Ravich, 2013), and analyze teacher preparation from point of view of scholar-practitioner (Moss, 2004). Patchen and Crawford (2011) used teacher-generated metaphors to understand epistemological positions on teacher challenges. Telling stories of experience has also been used as part of teacher education and professional development 
trainings (Ackerman \& Maslin-Ostrowski, 1995; Danzig, 1997; 1999).

Scholars have also emphasized the need for a narrative lens in leadership research (e.g., Klenke, 2008; Ospina \& Schall, 2001; Shamir \& Eilam, 2005). Said Klenke (2008), "Stories help us make sense of what we are, where we come from, and what we want to be" (p. 244). This pattern of self-identification (who I was, who I am, and who I am becoming) formed the conceptual framework that guided this study, as outlined in the following three reflective narratives approaches: Storytelling, symbolic interactionism, and anticipatory reflection.

\section{Conceptual Framework.}

Storytelling (Past Experiences). Stories are ways of making meaning of and communicating about who we are as reflected by our past experiences. Through stories we interpret the world, make sense of experience, claim identities, and reveal connections between the self and social structures (Riessman, 2005). Ackerman, Maslin-Ostowski, \& Christensen (1996) blended both educator and leadership experiences through a casestory method by inviting educators to create scenarios around personal leadership practice and dilemmas (case-stories) from their past experience. Through structured sharing and feedback, educators were able to help one another gain insight and perspective and grow professionally (1996). Drawing from this approach, narrative storytelling (written, verbal, or visual/arts-based) offers a unique opportunity to examine and make meaning of one's personal experience as a leadership educator, and also reveal collective themes or discourses that shape the field of leadership education.

Symbolic Interactionism (Present Beliefs). Symbolic interactionism suggests that one's beliefs and basis of understanding of the world is shaped by the social process of learning and transmission of information from others (Blumer, 1969). This information can come in a variety of forms including the use of language and symbols, providing a means by which individuals can negotiate meaning (Benzies \& Allen, 2000). Images are one medium that can be used to uncover symbolic meaning in that the interpretation of an image can be reflective of one's beliefs and perspectives. These beliefs and perspectives can serve as a reflection of one's professional identity in terms of how they see themselves (Walkington, 2008) as well as their behaviors in practice (Benzie \& Allen, 2000). The use of symbolic interactionism as a framework is not limited to this study alone; it has been used as a framework for different types of narrative studies investigating teachers' professional identity (e.g., Smith \& Fritz, 2008).

Anticipatory Reflection (Future Practices). While we often equate reflection with looking back, Conway (2001) suggests that reflection can also be anticipatory (prospective). Conway (2001) describes a process of anticipatory reflection using a storyline activity to "reconstruct anticipations" (p. 93) of student teachers' experiences during their intern year. Anticipatory reflection involves imagining the self in future contexts and creating new constructions of the self as a professional in practice (Conway, 2001). It is thinking about what will happen; more specifically drawing on prior knowledge relevant to future experience. Similar to the discovery and dream stages of 
Appreciative Inquiry (Cooperrider, Whitney \& Stravos, 2008), anticipatory reflection draws on memories that then play a role in opening the door to imagine an ideal future practice. Visualizing future practice can help leadership educators "see" what they want to future to be so they can engage in development, training, and practice in the present to situate themselves for future success.

\section{Method}

Our qualitative study was framed within an interpretive inquiry paradigm, in which personal narratives served entry points for examining one's lived experience in relation to historical, social, and cultural contexts (Kim, 2015). We utilized paradigmatic narrative inquiry, or analysis of narratives through forms of categorization (Polkinghorne, 1995). First, we collected data using three narrative methods (storytelling, symbolic interactionism, and anticipatory reflection) to capture short stories of lived experiences and life perspectives. Through these exercises, participants were "active interpreters of their own life experience rather than as mere reporters of their life stories" (Kim, 2015, p. 126). Then, we then used a variety of analytic tools to examine and categorize these stories to make meaning of past experiences, present beliefs, and future practices. In addition to individual analysis by narrative type, we also looked at all narratives collectively for more holistic meaning.

Setting and Participants. Participants in this study were recruited during a 2.5 day professional development experience for leadership educators. Due to the high number of possible participants, this event appeared to be a valuable data collection space. Participation in the study was not a condition of participation in the event. An explanation of the study was given on the first day, and 54 participants ( 29 female and 25 male) voluntarily consented to participate. The participants varied in years of professional experience $(0-3$ years $=22 ; 4-6$ years $=12 ; 6-10$ years $=7$, and more than 10 years $=13$ ).

Researcher Stance. Our position as researchers can be understood through our participation, and beliefs and assumptions about interpretation and (re)presentation. We negotiated multiple roles during the research process, participating as part of the curriculum design and on-site facilitation team at the event. As such, we engaged in multiple personal and professional conversations with participants, both related to and apart from this study. The data collection exercises were embedded within a broader professional development curriculum, and informed by our own prior scholarly work on the topic of leadership educator identity development. As reflexive researchers, we recognize that all empirical data is the result of interpretation (Alvesson \& Sköldberg, 2009). The process of interpretation requires us to be attuned to not only the theoretical assumptions, language, and pre-understanding guiding our work, but also aware of the intellectual, contextual, and cultural assumptions of our own communities of practice within the field of leadership education (2009). Inspired by Bahktin's concept of polyphony, we did not pursue an objective truth, but sought to represent leadership educator identity through multiple voices, as a co-constructed (re)presentations based on dialogical truth (discovered through interaction and collaboration) (Kim, 2015, p. 75). 
Data Collection. Data were collected during the conference as part of three intentional professional development activities based on our conceptual framework, which represented the past, present, and future: storytelling, symbolic interactionism, and anticipatory reflection.

Exercise 1: Critical Incidents Stories (Past Experience). Participants were organized into small groups of 8-10 people, with a facilitator in each group. The facilitator shared an overview of storytelling as a leadership learning technique and introduced a guiding question: What was a moment that mattered in my leadership educator journey? Participants were asked to free-write for 10 minutes around this prompt to form a critical-incident case-story and individually (re)told their case-story within the small groups. Small groups then discussed common themes or patterns they heard among the collection of individual stories. The exercise concluded with a wholegroup sharing of themes, as well as a few reflections on the experience of storytelling. Participants' written stories were collected, scanned, and returned to participants.

Exercise 2: Symbolic Interactionism (Representations of Present Beliefs). In this session, participants returned to their small groups with one facilitator. This activity utilized a deck of pre-printed cards with different images laid out in the center of the table (e.g., gardener, sculpture, maze, canyon with bridge, lion tamer/circus, computer/machine, globe). First, participants were asked to select an image (or create their own) and respond in writing (5 minutes) to the prompt: Describe how this image represents your interpretation of leadership education. Then, each person shared their images and reflections within their small groups. Facilitators used the following prompts for discussion: a) What do these images surface about our beliefs about leadership education? What are the underlying assumptions about leadership educators or leadership education practice? b) Where do these come from and how do they impact us as leadership educators? c) How did you come to this belief? Has anything you learned at [academy] challenged this belief? d) If this belief were not true, how might that impact what and how you educate on leadership? and e) How do you uphold this belief in practice as a leadership educator? The activity concluded with sharing insights with the large group. The written reflections were collected, scanned, and returned to participants.

Exercise 3: Anticipatory Reflection Letters (Future Self). This activity began with an individual reflection prompt: Think of an example of something you facilitated/taught in the past in regard to leadership that you wish you had a chance to do over again. What was the situation/context? What did you do? What was the outcome? Participants were asked to pro-flect by rewriting this story in the form of a letter to their future selves: Based on what you know now ... how would you like it to go next time you teach/facilitate it? What barriers might you encounter and what might help you? What else might you need? After 15 minutes of writing, participants shared their narratives in pairs and then small groups. Facilitators used the following debrief question for small group and large group discussion: a) What was the value of combining reflection with pro-flection? b) What did these stories reveal about our learning at this event? And, c) how can you continue to use these strategies to improve your practice? Facilitators collected the letters, scanned them, and returned them to participants. 
Data Analysis. To analyze the data, we created an archive of all the scanned handwritten documents submitted by participants (41 critical moments, 41 symbolic interactionism, 33 anticipatory reflections), which were then transcribed into text files. Each consenting participant was assigned a numeric code between 100-154 to maintain confidentiality. We used NVivo10 to manage our qualitative analysis process. First, we read through all of the data sets and took notes to help focus our analysis (Creswell, 2007). We developed an initial code list based on the theoretical and conceptual framework. Both authors coded a sample document separately and then used an inter-rater reliability query to compare codes and reach inter-rater agreement. Additional descriptive codes were added to the code list; however, we also used descriptive and in-vivo codes to remain open to emergent ideas (Saldaña, 2009). Utilizing analytic queries, we searched for patterns in the data that represented both unique and across-story themes. Through interpretive memoing, diagramming, and peer debriefing we connected ideas to the analytic framework (Corbin \& Strauss, 2008).

\section{Results}

While the themes of the narrative interventions represent the past, present, and future, our findings do not represent a temporal journey narrative. Rather, they represent a set of rhizomatic stories (Serminj, Devlieger, \& Loots, 2008), or multiple entry points into educators' journeys. Each entry point offers a temporary representation of selfhood. The polyphony, or multiple voice voices (Bahktin, 1981), illustrate how past experiences, present beliefs, and future intentions are interconnected, and how those connections represent and shape leadership educator professional identity.

Theme 1: Stories of Past Experience. Through exploring narratives of "moments that mattered" to leadership educators, we identified three categories of critical incidents shaping participant's perceptions of themselves and their role: past leadership experience, professional experience, and leadership educator as leader.

Past Leadership Experience. When reflecting on a critical moment in their leadership educator journey, eleven participants described moments relating to their own experience in leadership roles or experience as leaders. These included incidents of conflict that led to a change in their self-perception as a leader or movement toward an approach to leading that was more collaborative and inclusive. For example,

I was typically a manager and a very controlling group member. One meeting [with] the board, in which I had a rather "controlling" conflict with a committee chair (in front of all other board members), really flipped the switch with how I needed to learn to become more collaborative and a better team player. (100)

Participants also described how the knowledge and experience gained through training, courses, or assignments created "aha" moments that resulted in shifts in thinking about their own leadership philosophy and practice. 
Prior to [role] I was always focused on myself as the leader and what I produced .... And then, in my first year as a professional at [University] I attended the undergraduate interfraternity institute as a small group facilitator. There I was introduced to the [Five Exemplary Practices of Leadership] and realized that everyone has the potential to be a leader-it's not about the title. ... From this point [forward] I focused on all of those necessary pieces - going back to the values and that for evaluation to occur there had to be collaborative relationships. It couldn't be about just me I had to enable others to act. (122)

Taking on new roles or positions of leadership challenged and reinforced leadership beliefs and practices.

... I was reassigned ... I want to develop my leadership skills to improve my ability to lead a team of individuals to work towards a common goal. I have a strategic plan to improve motivation and buy-in, use strengths on my team and to increase the productivity. (128)

Failure (not achieving a leadership position or role) was also noted as influential to participants' personal development as a leader and future leadership action.

... these experiences taught me about how to handle rejection and to use the experience as a learning opportunity. Both of these opportunities allowed for feedback and I was able to use that feedback when exploring other leadership opportunities ... The meaning I have derived from this experience has inspired me to develop a leadership workshop on how aspiring student leaders can handle rejection, strategies for learning from the experience, and how they can cope through the experience. (113)

Professional Experience. Twenty-seven participants surfaced four sub-categories of critical incidents related to their professional experience in leadership education. The first category was related to developing or growing a leadership program and included starting a program, creating resources for other leadership educators, or being invited to serve on a strategic planning team. Participant 141 offers a description of this when saying,

I have an opportunity to step back and be part of determining the big picture of what leadership education is at [University], how leadership education occurs in the minor and in the co curriculum, and how we will evaluate what students learn. (141)

Another category of professional experience was related to experiences in classroom, program and/or course development that led to reflective insight and resulted in integrating new ideas into curriculum or practice. 
... it dawned on me that I was helping students check a box off the list \& prepare them to get in the door, but these students were not equipped to exercise leadership. I realized these students purpose often time did not align with what they were doing \& their motivations were not congruent to any form of desire for the impact of the work they were doing, which impacted their action \& reactions within the experience. I knew I needed to provide something that had depth \& grounded students in learning that would influence decisions, how they responded in their environment \& rituals or habits that could be a foundation for approaching experiences \& life in greater context. (120)

Participants also identified conference experiences (e.g., as both a participant and in a facilitator role) as important to self-reflection and personal change. Finally, some found that they did not have one experience, but that their journey was about finding meaning/congruence between values and career by trying out something new (e.g., travel, different position, taking a risk). For example, one participant said of a moment in their gradual, evolving journey: "I needed to get away for two reasons: 1. To figure out whether I wanted to stay in higher ed or not, and 2. To explore more of the world and become culturally competent" (103).

Leadership Educator as Leader. Six participants made explicit connections between the role of teacher/educator and leader. This occurred in two distinct ways. The first reflects the notion that students see educators as leaders.

He paused, looked me straight in the eyes and with almost tears in his eyes he said "I want to be like you." This was a shock to me because I didn't at that time think that as a teacher (instructor) I acted as a leader. He stated that he observed me in the classroom, in the hallway, and in formal meetings and he though that's the type of behavior he wanted to follow. That was a huge eye opening \& a huge responsibility to ensure that I am very careful about my everyday actions. (116)

The second notion that emerged is that teaching requires one to continue learning, and how we integrate that learning has direct implications for students. Because students see teachers as role models, bringing personal stories into the classroom can serve as a way to illustrate the leadership concepts we are teaching.

Being assigned to teach a class on global leadership and [pondering] the role of my experiences and how they could be reflected in the course in a way that positioned me as more than just an instructor but as a person with actual experiences that can be used to explore concepts. I did not reveal myself during the first semester, but did so after my second semester and realized that I couldn't teach the class effectively without inserting myself in it. (125) 
Theme 2: Symbolic Representations of Present Beliefs. In this exercise, participants selected an image they believed served as a metaphor for leadership education and wrote a caption with that image. Most frequently described images/metaphors were related to nurturing plants/gardening (11), crossing a bridge (10), navigating a maze (7), and a globe (6). Data gathered from this exercise was much more variable, ranging from a few words to a few sentences. Regardless of the image selected, participants' responses fell into four main categories: Beliefs about leadership (37), beliefs about leadership education (13), beliefs about teaching leadership (53), and beliefs about students (7). Some participants' responses were solely reflective of one category, whereas others represented more than one category.

Beliefs about leadership. Participants' responses related to their beliefs about leadership reflected a variety of concepts, with some even discussing that they believe there are many different definitions of leadership. One participant noted, "There are multiple approaches to leadership and paths to take to effectively lead others" (139). Words or concepts most frequently used to describe leadership were process-oriented, complex, contextual, change-oriented, and goal-oriented. Additionally, participants highlighted descriptors such as relational, experiential, ethical, inclusive, social justice oriented, related to growth and development, uncertainty, and "culturally and socially mediated" (125).

Beliefs about leadership education. Those who described their beliefs about leadership education through this activity discussed how leadership education is a personal growth and development process, specifically, a process of developing other leaders. For example, one participant believes leadership education involves "Developing people to lead for the betterment of local and global communities (107). One participant elaborated on a metaphor of growth, "In leadership [education] we plant seeds that sprout not knowing what fruition will look like. The plant may flourish or it may wilt. Have I done my best to nourish it?" (140).

Beliefs about teaching leadership. If leadership education is a process of developing other leaders, then beliefs about teaching leadership describe more specifically what this process looks like. The participants' stories suggested that leadership educators facilitate and guide students by recognizing their potential and providing support, care, and resources so they can begin to see the world in new and interconnected ways as well as flourish in their own development. They acknowledged that students also have agency by choosing to engage in their own leadership journey. One participant said,

There are times when the instructor goes before the students - identifying the goals, and steps toward learning outcomes. Students may follow our lead and go forth. There are also times when the students must step out and forge their own way. The teacher must be open to both experiences. (106)

Teaching leadership requires the development of mutual, reciprocal relationships. It requires trust between teachers and students; both must be willing to engage 
courageously in a process, adapt, grow, and serve in a space that is intellectually challenging and the future is often unknown.

Beliefs about students. Beliefs about students centered around recognizing that each student has unique talents and needs. One participant noted that "Each participant is in different places and spaces which informs their leadership development journeys" (123). Participants also emphasized that students have potential and capacity to exercise leadership - to become leaders themselves. "[The] student is the seed. Their potential is to become a leader, just as a seed becomes a plant" (135).

Theme 3: Intentional Future Practice - Thinking Back, Thinking Forward. Anticipatory reflection involves imagining the self in future contexts and creating new constructions of the self as a professional in practice (Conway, 2001). It is thinking about what will happen; more specifically drawing on prior knowledge relevant to future experience. Participants were asked to respond to a prompt about an experience they wished they could do again and then write a letter to their future self with advice. Based on reflection of past experience, participants shared feedback and advice for improving their own leadership education practice in light of new professional learning. We identified two primary categories: personal (both intra- and inter-personal) and procedural (knowledge and skills related to teaching and learning, specifically content, pedagogy, and structures of learning). These categories integrate ways of knowing and being that represent intentions of good practice. Analyzing across the categories we found these intentions could be further described by Seemiller and Priest's (2017) dimensions of LEPID: cognitive (What do I need to know?), experiential (What do I need to do?), and emotional (How should I feel?).

Personal (Intra). When describing their experience and aspiration for the future, 11 participants' reflections related to intentions of self: Overcoming fear, challenging assumptions, being vulnerable, and overcoming insecurity. Within these examples, participants shared cognitive intentions such as, "Make sure you step back, breathe, challenge your assumptions and biases - and most importantly get out of the way" (152). Cognitive intentions were closely related to experiential intentions in this sub-category. For example, one participant encouraged himself to, "Take a look at [listening] and following each and every inner voice, trust [it], [and] focus in what you are sensing and [channel] it [into] [a constructive] follow up each and every time, [consistently]" (119). Six examples also reflected the emotional dimension. For example, "I think it came from a place of insecurity ... and I have a huge fear of being (or appearing) irrelevant to my students as a younger educator who prides himself in designing high impact, highly relevant programs" (121).

Personal (Inter). Seven participants offered 10 examples that construct this sub-category. Common to these examples is an emphasis on relational intentions; for example, intentions to build community and offer support and guidance to students in meaningful ways. One participant was thoughtful about the impact of his words in how his students think, 
When you have [discussions with] students about their stress over future plans and changing the world, be careful about how you encourage them to narrow their focus. Though you know what you mean, it might get misinterpreted. Though you just want them to not be stressed by the daunting challenge to change the world - like you were at their age-do not try and cause them to only focus internally or on a very small sphere of influence. This might enable or encourage selfish thoughts. It even could make them think that their legacy isn't important at all. (132)

This intention reflects both cognitive and experiential dimensions. A further experiential example was from a participant who urged herself to "Spend more time creating a community of learners in the classroom and allow them more opportunities to be the expert in their stories" (124). The emotional dimension was expressed as one participant discussed the intention of setting classroom expectations that would help to redirect "a negative student" in a more productive way (108).

Procedural (Content). Nine participants referenced the intended use of specific theories or sources of content in their reflections. This sub-category included references to specific content topics or the use of theory in general. Within these examples, six participants shared cognitive intentions. For example, "The next time I teach the first class for a leadership course, I will have the knowledge of different theory and pedagogy to successfully plan and prepare" (107). Seven participants identified experiential intentions, "There is a need to teach the theory- transactional, laissez faire, transformational, and authentic" (101). None of the content-related intentions described how the educator should feel, although one participant commented that "Students want to feel their time matters" (129). Thus, it is important to be prepared, use a "theory that works well and has a good activity" that "allows students to see the bridge between theory and practice" (129).

Procedural (Pedagogy). Anticipatory reflection stories included advice on specific pedagogical choices (26 examples from 20 participants). The examples in this sub-category ranged from very specific steps or strategies to broader reminders to implement ideas or activities learned from the Academy. This sub-category emphasized including students' perspectives by utilizing a more student centered approach with shared power and student input. Participants also described the intention to create more engaged and active learning through activities, discussion, and reflection.

Of these pedagogical examples, 14 were identified as cognitive intentions. One participant shared, "... remember what you've learned at [Event] and seek always active engagement, active learning, and powerful reflection - in individual and group assignments" (106). There were 23 examples of experiential intentions, like this specific directive to "Start the session with higher expectations \& have students come up with rules of engagement in the workshop" (108). Ten participants also integrated the emotional dimension into their descriptions of pedagogy. For example, "Most of all, always remember to have fun and trust me, you'll enjoy the overall experience!" (147). 
Procedural (Structures of Learning). This sub-category includes 13 examples from 11 participants on program, course, or assignment design. While some of these examples included pedagogical choices, in general they speak more holistically to planning tasks. Participants highlighted the need to align goals/objectives, learning activities, and assessment. They also described the need to develop student or staff training.

There were 11 examples of cognitive intentions. In the following example, a participant asks (and answers) important questions about her program:

What is the point of this program? What can students effectively learn and apply in whatever amount of time you have. Then, how will you measure that learning and application? Consider who else wants to see those results and how they will inform your work. Arm yourself with preparation, intentionality, and care before embarking on the journey. However, be prepared to adapt to your students' needs while still achieving your outcomes. (126)

The second most frequent set of intentions with twenty participants was related to experiential structures of learning. In these examples, participants offered specific instructions or directives for themselves. On participant shared, "In the future take planning time seriously and give it the time and attention it deserves. Focus on creating learning goals and matching the activities to the stated objectives" (124). Another participant reminded himself to "Prepare ... for the barriers that may arise as you acknowledge that not all students in the class, or in assigned groups, have the same motivation, knowledge, or other situational factors" (106). The emotional dimension was least frequent within structures of learning (8 examples). Emotions ranged from nuanced intentions for interactions "you can let them know you're happy to hear from them" (154) to a more direct imperative of "Don't doubt your ability!" (126).

While the procedural category highlights intentions of best-practice around content, pedagogy, and structures of learning, it also illustrates how these intentions are integrated by cognitive, experiential, and emotional dimensions. Past experience generated feelings that led to learning/knowledge which prompted new ways (intentions) of doing in the form of future-oriented best-practices. Almost one-third of intentions were coded as both cognitive and experiential - participants would tell themselves what to "do" based on what they need to "know," as illustrated by this example:

The next time I teach the first class for a leadership course, I will have the knowledge of different theory, and pedagogy to successfully plan and prepare. I will have specific outcome/goal in mind for the course and will guide the students in that direction. I will have specific learning activities that are intentionally shaped. (107) 


\section{Discussion}

Our study sought to describe professional identity constructions of leadership educators participating in a professional development event through the following questions: 1) How do participants describe critical moments in their leadership educator journey (past experiences)? 2) How do participants describe their beliefs about leadership education (present beliefs)? And, 3) How do participants express intentions for future leadership education practice (future practices)? Participants' narrative (re)presentations of self illustrate small snapshots into past, present, and future experiences. While the stories shared by participants were unique to each individual, the aggregate collection of these stories allowed us to uncover themes reflective of shared meanings.

Past Experiences. Seemiller and Priest (2015) describe critical incidents as important shapers of leadership educator identity. Through this study, participants described positive or negative moments in their professional experience that led to a shift in thinking or practice. Their stories emphasized how experiences such as developing programs, attending trainings, or trying new curricular approaches helped them develop new insight or change their practices.

The stories also highlighted how for some participants, past leadership roles and experiences shaped their views of self as a leader, and their understanding of leadership and learning. In addition to the role of prior leadership experience on one's identity, perceptions of being a leader also emerged in our findings as being influential to professional identity. Some participants described how they are perceived as leaders by their students, and they recognize that modeling leadership concepts and practices to their students motivate their students to learn and develop. Thus, our findings indicate that leadership educators' can also hold a leader identity, what Day, Harrison and Halpin (2009) define as a "sub-identity that an individual holds regarding his or her role as leader" in terms of both formal roles and processes by which one comes to those beliefs (p. 183). This prompts a critical question: Is holding a leader identity a necessary requirement of leadership educator professional identity?

Present Beliefs. Participants used symbolic images to describe their own meanings of leadership education. While these stories were very brief, often only a few words or phrases, we were able to construct interpretations of how educators' perceptions influenced their professional identities. Participants believed leadership to be a process that is complex, relational, and contextual. Additionally, leadership was described to be oriented toward change; not only individual growth and development, but also towards a more ethical, inclusive, and socially just world. These views seem to align with contemporary, post-industrial leadership perspectives (e.g., Komives, Wagner \& Assoc., 2016). Beliefs about teaching leadership suggest that form or structure of leadership education should align with these values, process, and purpose. Meaning, to develop leaders who have the potential to lead in relational, contextual ways requires creating the conditions for learning leadership as a complex, relational, contextual process. Being a leadership educator is being a developer of leaders through exercising leadership.

Future Practices. Participants reflected on memories of a "failed" or "bad" experience and imagined themselves applying a new strategy to create an ideal future context. In doing so, 
they generated new constructions of self in the practice of leadership education, surfacing cognitive, experiential, and emotional dimensions of practice. While each person's past story was unique, their collective insights contribute to what Conway (2001) describes as "a phenomenology of learning to teach" (p. 93); insights into the ways of knowing and being that represent "good" leadership education practice.

\section{Recommendations}

Stories can provide a gateway to the hearts and minds of individuals by offering opportunities for them to share thoughts, feelings, experiences, and examples in their own words. Rich data generated from individual stories can be useful; however, our participants' collective story offers insight into recommendations for practice related to leadership educator preparation and professional development. Key ideas, issues, and concerns from the participants' narratives provide the foundation for the following four recommendations.

Reflection. The use of narratives proved to be a powerful research methodology, yet the process-oriented nature of narratives also offered a self-reflective experience for participants to uncover their thoughts and feelings about their professional identities. We recommend that leadership educators dedicate time for self-reflection around their professional identities as a way to both make meaning as well as consider next steps in their identity development. Questions can center on one's definition of leadership, what makes an effective leadership educator, greatest lessons learned as a leadership educator, hopes and fears as a professional, and the vision for one's future as a leadership educator. This reflection can take place through journaling, artistic expression, or structured dialogue.

Communities of Practice. Seemiller and Priest (2015) found that communities of practice are significant shapers of professional identity in that they offer the opportunity for leadership educators to engage in dialogue, exchange feedback, and explore ideas with others. These interactions can influence what these educators know, how they feel, and how they act, ultimately contributing to their professional identity development (Seemiller \& Priest, 2017). For newer professionals who are grappling with their own beliefs around leadership and leadership education, communities of practice offer a space for them to explore their beliefs with others who have many years of experience and expertise.

It is important that leadership educators focus on engaging in communities of practice as a means to enhance their professional identity development. Communities of practice can include colleagues in their own workplaces, if possible, as well as other professionals through associations, conferences, and professional involvement. In addition to formal connections, informal connections such as participating in social media groups, chat rooms, and group research and writing opportunities can offer the benefits of a community of practice.

Training. It is apparent from our study that many of the scenarios that leadership educators chose to rewrite reflected instances of developing more competence in both the content and instruction of leadership education. This aligns with the findings from Seemiller and Priest (2017) in their uncovering of the prominence of the imposter syndrome for newer professionals. 
Given this, we recommend providing more intentionally designed, developmental training for leadership educators to help them lay the groundwork for effective practice. Enhancing their teaching capacity will likely enhance their competence and confidence, ultimately reducing the extent that they long for a "re-do" of an educational scenario.

Practice. As educators, we think of practice as practicing teaching or leadership development. However, practice also entails practicing being a leadership educator. That means utilizing space, sought out on one's own or provided more formally through conferences and programs, to be able to reflect on issues of professional identity as they relate to the role of the leadership educator. Educators must practice authenticity in sharing their successes and shortcomings both as a leader and as an educator. And, this sharing must not simply be with colleagues, yet with the students who are experiencing their own leadership journeys. By practicing being a leadership educator, students can see that leadership is messy, human, and complex. And, how can we ask students to practice if we as educators do not do our part?

\section{Recommendations for Future Research}

We propose four recommendations for future research. First, while our study answered the call for narrative approaches to leadership research (Klenke, 2008), additional qualitative study is needed. The use of art, ethnography, and discursive approaches could offer additional lenses to describing the varied experiences and perspectives of leadership educators. Increased understanding of leadership educator identity could support the intentional design of pathways into the field, including interventions that contribute to movement through LEPID spaces of exploration, experimentation, validation, and confirmation (Seemiller \& Priest, 2015; 2017).

Second, our study involved capturing stories representing three points in time (past experience, present belief, and future practice). However, all stories were collected simultaneously and our findings are limited to (re)presenting characteristics or constructions of professional identity, rather than the actual process of identity development. Longitudinal studies that follow a cohort over time could provide a more linear narrative to the process of leadership educator identity development.

Third, the methods used in this study were three narrative exercises conducted as part of a professional development training. While the methods were designed to collect stories of experience that aligned with our conceptual framework, we did not collect data to evaluating the validity of the exercise (i.e., Did the exercise itself contribute to participants' identity development?). Future research may include an evaluative of the exercises as not only pedagogical professional development tools, but also their potential to serve as valid research assessments.

Finally, our study clearly indicated a connection between leader identity and leadership educator identity. But what this connection is, how it is formed, and how these identities intersect remains unknown. Future research on the intersectionality of leader and leadership educator identity could help shed light on how these identities inform each other. 


\section{Conclusion}

Past experiences shape present beliefs, present beliefs influence future practices, and intended future practices reveal target areas of learning derived from past experiences. The past experiences, present beliefs, and future practices described by participants are not only representations of their own leadership educator identity, but can provide a road map for leadership educator preparedness.

What leadership educators believe and do impacts students. The notion that leadership educators somehow leave their own leadership experiences, beliefs, and ideas for improving practice at the door means that either we as a profession are asking for inauthenticity or we are simply not acknowledging that what educators bring to the learning environment is more than just expertise and effective instructional practice. What students learn from educators is beyond what the curriculum entails; like all individuals, leadership educators are constantly changing and developing as educators, leaders, and humans, influencing both their professional identities and their embodiment of those identities.

Leadership educator identity is shaped by multiple incidents and influences that cut across points in time (Seemiller \& Priest, 2015; 2017), making it a complex concept to fully understand. And, given the lack of research on the topic, it is critical that we turn our attention to future research in this area. Other professions have vast bodies of work on professional identity, and as our profession continues to grow, we need to better understand not just what we do, but who we are.

\section{References}

Ackerman R., \& Maslin-Ostrowski, P. (1995). Developing case stories: An analysis of the case method of instruction and storytelling in teaching educational administration. Paper presented at the Annual Meeting of the American Educational Research Association, San Francisco, CA.

Ackerman, R., \& Maslin-Ostrowski, P. (1996). Real talk: Toward further understanding of case story in teaching educational administration. Paper presented at the Annual Meeting of the American Educational Research Association, New York, NY.

Alvesson, M., \& Sköldberg, K. (2009). Reflexive methodology: New vistas for qualitative research (2nd ed.). London: SAGE.

Andenoro, A. C., Allen, S. J., Haber-Curran, P., Jenkins, D. M., Sowcik, M., Dugan, J. P., \& Osteen, L. (2013). National leadership education research agenda 2013-2018: Providing strategic direction for the field of leadership education. Retrieved from http://www.leadershipeducators.org/ResearchAgenda 
Beauchamp, C., \& Thomas, L. (2009). Understanding teacher identity: An overview of issues in the literature and implications for teacher education. Cambridge Journal of Education, 39(2), 175-189. doi:10.1080/03057640902902252

Bakhtin, M. M. (1981). The dialogic imagination: Four essays by MM Bakhtin (M. Holquist, Ed.; C. Emerson \& M. Holquist, Trans.). Austin, TX: University of Texas Press.

Beijaard, D., Meijer, P. C., \& Verloop, N. (2004). Reconsidering research on teachers' professional identity. Teaching and Teacher Education, 20(2), 107-128. doi:10.1016/j.tate.2003.07.001

Benzies, K. M., \& Allen, M. N. (2000). Symbolic interactionism as a theoretical perspective for multiple method research. Journal of Advanced Nursing, 33(4), 541-547. doi:10.1046/j.1365-2648.2001.01680.x

Blumer, H. (1969). Symbolic interactionism: Perspective and method. Englewood Cliffs, NJ: Prentice-Hall.

Brookfield, S. (2015). The skillful teacher (3rd ed.). San Francisco, Jossey-Bass.

Bruner, J. (2002). Making stories: Law, literature, life. New York, NY: Farrar, Straus, \& Giroux.

Coldron, J., \& Smith, R. (1999). Active location in teachers' construction of their professional identities. Journal of Curriculum Studies, 31(6), 711-726. doi:10.1080/002202799182954

Connelly, F. M., \& Clandinin, D. J. (1990). Stories of experience and narrative inquiry. Educational Researcher, 19(5), 2-14.

Conway, P. F. (2001). Anticipatory reflection while learning to teach: from a temporally truncated to a temporally distributed model of reflection in teacher education. Teaching and Teacher Education, 17(1), 89-106. doi:10.1016/S0742-051x(00)00040-8

Cooperrider, D. L., Whitney, D. \& Stavros, J. M. (2008). Appreciative inquiry handbook: For leaders of change (2nd ed.). San Francisco, CA: Berrett-Koehler Publications.

Corbin, J. M., \& Strauss, A. L. (2008). Basics of qualitative research: Techniques and procedures for developing grounded theory (3rd ed.). Thousand Oaks, CA: Sage Publications.

Council for the Advancement of Standards in Higher Education. (2009). CAS professional standards for higher education (7th ed.). Washington, DC: Author.

Creswell, J. W. (2007). Qualitative inquiry \& research design: Choosing from among five approaches. Thousand Oaks, CA: Sage Publications. 
Danielewicz, J. (2001). Teaching selves: Identity, pedagogy, and teacher education. Albany, NY: State University of New York Press.

Danzig, A. B. (1997). Leadership stories: What novices learn by crafting the stories of experienced school administrators. Journal of Educational Administration, 35(2), 122137.

Danzig, A. (1999). How might leadership be taught? The use of story and narrative to teach leadership. International Journal of Leadership in Education, 2(2), 117-131. doi: $10.1080 / 136031299293147$

Day, D. V., Harrison, M. M., \& Halpin, S. M. (2009). An integrative approach to leader development: Connecting adult development, identity, and expertise. New York, NY: Psychology Press.

Gee, J. P. (2000). Identity as an analytic lens for research in education. Review of Research in Education, 25(1), 99-125. doi: 10.2307/1167322

International Leadership Association. (2009). Guiding questions: Guidelines for leadership education programs. Retrieved from: www.ilanet.org/communities/LC/GuidingQuestionsFinal.pdf

Jenkins, D. M. (2012). Exploring signature pedagogies in undergraduate leadership education. Journal of Leadership Education, 11(1), 1-27. Retrieved from http://journalofleadershiped.org/attachments/article/109/Jenkins.pdf

Jenkins, D. M., \& Owen, J. E. (2016). Who teaches leadership? A comparative analysis of faculty and student affairs leadership educators and implications for leadership learning. Journal of Leadership Education, 15(2), 98-113. doi:1012806/V15/I2/R

Komives, S., Wagner, W. \& Associates. (2016). Leadership for a better world: Understanding the social change model of leadership development (2nd ed.). San Francisco, CA: JosseyBass.

Kim, J. H. (2015). Understanding narrative inquiry: The crafting and analysis of stories as research. Thousand Oaks, CA: SAGE Publications.

Klenke, K. (2008). Qualitative research in the study of leadership. Bingley, UK: Emerald Group Publishing.

Moss, G. (2004). A narrative analysis of scholar-practitioner teacher leadership preparation. Journal of School Leadership, 14(2), 171-194.

Nespor, J., \& Barylske, J. (1991). Narrative discourse and teacher knowledge. American Educational Research Journal, 28(4), 805-823. 
Ospina, S., \& Schall, E. (2001). Leadership (Re)Constructed: How lens matters. Paper presented at the APPAM Research Conference, Washington, DC. Retrieved from: http://wagner.nyu.edu/community/faculty/sonia-m-ospina\#showMore--773

Patchen, T., \& Crawford, T. (2011). From gardener to tour guides: The struggle revealed in the teacher-generated metaphors of teaching. Journal of Teacher Education, 62(3) 286-298. doi: $10.1177 / 0022487110396716$

Polkinghorne, D. E. (1995). Narrative configuration in qualitative analysis. International Journal of Qualitative Studies in Education, 8(1), 5-23. doi:10.1080/0951839950080103

Riessman, C. K. Narrative Analysis. Encyclopedia of Social Science Research Methods. SAGE Publications, Inc. Thousand Oaks, CA: SAGE Publications, Inc.

Sachs, J. (2001). Teacher professional identity: Competing discourses, competing outcomes. Journal of Education Policy, 16(2), 149-161. doi:10.1080/02680930116819

Sachs, J. (2005). Teacher education and the development of professional identity: Learning to be a teacher. In P. M. Denicolo \& M. Kompf (Eds.), Connecting policy and practice: Challenges for teaching and learning in schools and universities (pp. 5-21). New York, NY: Routledge.

Saldaña, J. (2009). The coding manual for qualitative researchers. Thousand Oaks, CA: Sage

Schultz, K., \& Ravitch, S. M. (2013). Narratives of learning to teach: Taking on professional identities. Journal of Teacher Education, 64(1), 35-46. doi: 10.1177/0022487112458801

Seemiller, C., \& Priest, K. L. (2015). The hidden "Who" in leadership education: conceptualizing leadership educator professional identity development. Journal of Leadership Education, 14(3), 132-151. doi:1012806/V14/I3/T2

Seemiller, C., \& Priest, K. L. (2017). Leadership educator journeys: expanding a model of leadership educator professional identity development. Journal of Leadership Education, 16(2), 1-22. doi:10.12806/v16/i2/r1

Sermijn, J., Devlieger, P., \& Loots, G. (2008). The narrative construction of the self: Selfhood as a rhizomatic story. Qualitative Inquiry, 14(4), 632-650. doi:10.1177/1077800408314356

Shamir, B., \& Eilam, G. (2005). "What's your story?” A life-stories approach to authentic leadership development. The Leadership Quarterly, 16(3), 395-41. Journal of Leadership Education, 8(1), 72-92.

Smit, B., \& Fritz, E. (2008). Understanding teacher identity from a symbolic interactionist perspective: two ethnographic narratives. South African Journal of Education, 28, 91-101. 
Sowcik, M., Lindsey, J. L., \& Rosch, D. M. (2013). A collective effort to understand formalized program review. Journal of Leadership Studies, 6(3), 67-72. doi: 10.1002/j1s.21259

Sutherland, L., Howard, S., \& Markauskaite, L. (2010). Professional identity creation: Examining the development of beginning preservice teachers' understanding of their work as teachers. Teaching and Teacher Education, 26(3), 455-465. doi:

10.1016/j.tate.2009.06.006

Walkington, J. (2005). Becoming a teacher: encouraging development of teacher identity through reflective practice. Asia-Pacific Journal of Teacher Education, 33(1), 53-64. doi:10.1080/1359866052000341124

\section{Author Biographies}

Dr. Kerry L. Priest (kerryp@ ksu.edu) is an Assistant Professor in the Mary Lynn and Warren Staley School of Leadership Studies at Kansas State University. Her undergraduate and graduate courses focus on civic leadership development, socially responsible leadership, community engagement and organizing. Kerry's research agenda explores the intersections of leadership development and engaged teaching and learning in higher education, with an emphasis on questions that emerge from interpretative, collaborative frameworks of social change. Her scholarship also addresses questions related to student leader identity and leadership educator identity. Kerry earned her Ph.D. from Virginia Tech and Master's degree from the University of Georgia.

Dr. Corey Seemiller (corey.seemiller@wright.edu) is an Assistant Professor in the Department of Leadership Studies in Education and Organizations at Wright State University and was formerly the Director of Leadership Programs at The University of Arizona. She has also held roles such as the co-chair for the National Leadership Symposium and the co-chair for the Leadership Education Academy. Dr. Seemiller is the author of The Student Leadership Competencies Guidebook and Generation Z Goes to College. Corey received her Bachelor's degree in Communication, Master's degree in Educational Leadership, and Ph.D. in Higher Education and has worked as a leadership educator for higher education, K-12, non-profits, military, and community organizations for more than 20 years. 